\title{
Some new Camallanoidea (Spirurida) Nematodes from Fishes, Amphibians and Reptiles. *
}

\author{
[Quelques Camallanoidea nouveaux (Spirurida) \\ Nématodes de Poissons, Amphibiens et Reptiles]
}

by Vinod AGRAWAL * *

\begin{abstract}
Abstraet
Cucullanus pseudeutropi n. sp. from Pseudeutropius garua (Cucullanidae Cobbold, 1864) is described. Three species of Camallanidae Railliet \& Henry, 1915 a:e described, namely, Camallanus mastacembeli n. sp. from Mastacembelus armatus; C. inglisi n. sp. from Rana tigrina, and C. bufonis n. sp. from Bufo sp. In addition Camallanides prashadi Baylis and Daubney, 1922 from Ptyas mucosus is redescribed.
\end{abstract}

\section{Résumé}

Cucullanus pseudeutropi n. sp. (Cucullanidae Cobbold, 1864) de Pseudeutropius garia est décrit. Trois espèces de Camallanidae Railliet et Henry 1915 sont décrites: Camallanus mastacembeli $\mathrm{n}$. sp. de Mastacembelus armatus; $C$. inglisi $\mathrm{n}$. sp. de Rana tigrina, et $C$. bufonis n. sp. de Bufo sp. En outre une nouvelle description de Camallanides prashadi Baylis et Daubney, 1922 de Ptyas mucosus est donnée. Lucknow.

* Part of thesis accepted for the degree of Doctor of Philosophy at the Lucknow University,

** Lecturer in Zoology Department, University of Lucknow, Lucknow, U.P. India.

The work has been carried out under the direction of Dr. S. P. Gupta, Department of Zoology, Lucknow University, Lucknow. The author is deeply indebted to him for his invaluable help and encouragement. Thanks are also due to Prof. G.S. Thapar, F.N.I. for kindly going through the manuscript and giving useful suggestions.

The paratype and holotype specimens of the forms described in this paper will be deposited in Dr. G.S. Thapar's Helminthological Collection, Lucknow. U.P. India. 
FAMILY - CUCULLANIDAE Cobbold, 1864

SUB-FAMILY - CUCULLANINAE Yorke et Maplestone, 1926

\section{CUCULLANUS PSEUDEUTROPI n. sp.}

(Fig. 1-4)

Two male and one female specimens were collected from the intestine of a fresh water fish, Pseudeutropius garua (Ham.) from river Gomti at Lucknow.
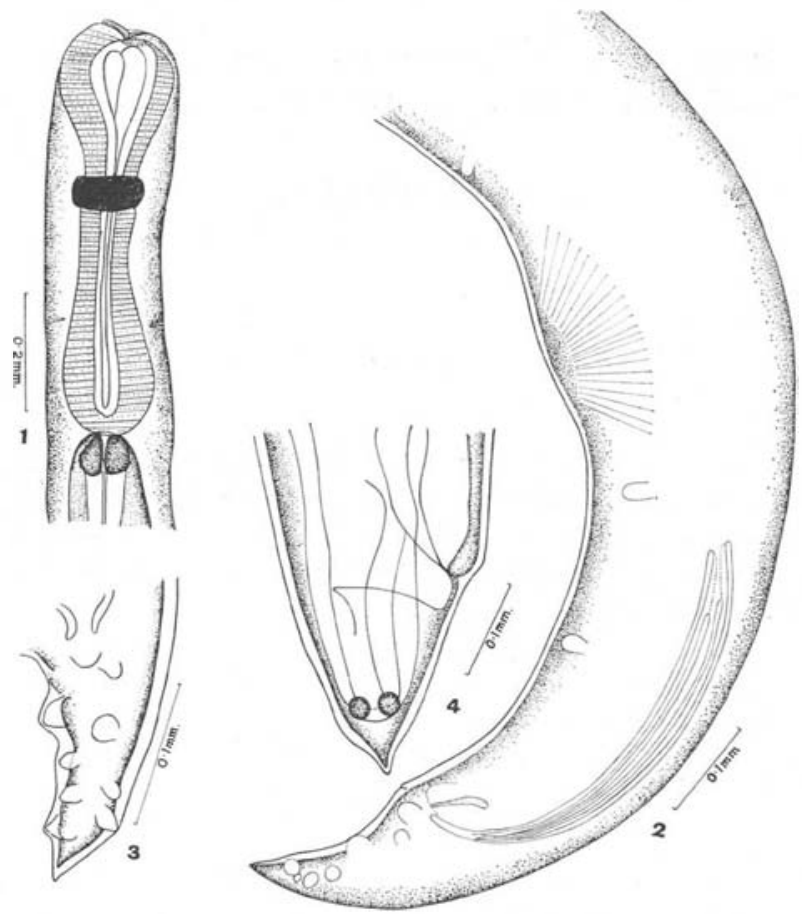

Fig. 1-4. - Cucullanus pseudeutropi n.sp.

FIg. 1. - Région antérieure du mâle. Vue latérale

Fig. 2. - Extrémité caudale du mâle. Vue latérale

Fig. 3. - Extrémité caudale du mâle. Vue ventrale.

Fig. 4. - Extrémité caudale de la femelle. Vue latérale

FIGS. 1-4. - Cucullanus pseudeutropi n. sp.

FIg. 1. - Anterior tegion of male. Lateral view

FIG. 2. - Male tail. Lateral view

FIG. 3. - Male tail. Ventral view

Fig. 4. - Female tail. Lateral view 


\section{Deseription :}

Body elongated, cylindrical, medium sized, anterior extremity bent dorsally. In end on view mouth triangular, bounded with two large lateral lips at sides. Each bearing three well developed papillae. Behind mouth opening, a lining of dentigerous membrane. Esophagus muscular, lacking a glandular portion, club shaped and dilated anteriorly to form a pseudobuccal capsule. Intestine simple without any diverticulum. Cephalic glandis absent. Two lateral narrow alae extending throughout body length. Cuticle finely striated transversely, striations 0.005 to $0.009 \mathrm{~mm}$. apart from each other.

Male: Body 7.15 to $10.16 \mathrm{~mm}$. long, 0.38 to $0.41 \mathrm{~mm}$. wide. Head 0.14 to $0.15 \mathrm{~mm}$. in diameter. Two small cervical papillae bristle like 0.57 to $0.61 \mathrm{~mm}$. from anterior extremity. Anterior dilated pseudobuccal capsule, 0.21 to $0.22 \times 0.17$ to $0.18 \mathrm{~mm}$. and posterior muscular œsophagus 0.43 to $0.48 \times 0.13$ to $0.17 \mathrm{~mm}$. Entire œsophagus 0.65 to $0.69 \mathrm{~mm}$. long. Nerve ring 0.25 to $0.26 \mathrm{~mm}$. and excretory pore 0.29 to $0.31 \mathrm{~mm}$. from anterior end. Tail pointed, $0.18 \mathrm{~mm}$ long. Caudal end curled ventrally and forms a single turn of a spiral. Caudal alae narrow. Nine pairs of pedunculated caudal papillae with four pairs preanal and five pairs postanal. Of preanal papillae one pair anterior to anal sucker and rest of three pairs situated one behind other. A pair. of phasmids observed at tip of tail. Spicules equa!, similar, tubular, funnel shaped, broader at anterior end while sharply pointed at posterior end. They measure 0.49 to $0.52 \mathrm{~mm}$. in length. Gubernaculum wedge shaped, 0.062 to $0.10 \mathrm{~mm}$. in length. Preanal sucker muscular, spindle shaped, 0.16 to $0.20 \mathrm{~mm}$. in length and situated at 0.40 to $0.45 \mathrm{~mm}$. from cloacal aperture.

Female: Body $11.68 \mathrm{~mm}$. long, $0.45 \mathrm{~mm}$. wide. Head $0.15 \mathrm{~mm}$. in diameter. Two small cervical papillae bristle like $0.65 \mathrm{~mm}$. from anterior end. Anterior dialted pseudobuccal capsule, $0.22 \times 0.16 \mathrm{~mm}$. and posterior muscular cesophagus, $0.52 \times$ $0.17 \mathrm{~mm}$. Entire œsophagus, $0.74 \mathrm{~mm}$. long. Nerve ring $0.27 \mathrm{~mm}$. and excretory pore $0.33 \mathrm{~mm}$. from anterior end. Tail short, pointed without any lateral papillae. Vulva postequatorial $4.56 \mathrm{~mm}$. from hind end of body. Two ovaries ; Uterine branches opposed; Oviparous. Eggs thin shelled, 0.04 to $0.08 \times 0.02$ to $0.04 \mathrm{~mm}$. in size.

Host: Pseudeutropius garua (Ham.).

Location: Intestine.

Locality: Lucknow.

\section{Discussion :}

The new form is referred to the genus Cucullanus Mueller, 1777. Yamaguti (1961) has listed 60 species of this genus from fishes from various parts of World. No form of the genus hither been described from fishes. Khera (1954) claimed that C. antipodeus Baylis, 1932 was found in Mystus seenghala from Lucknow. Cucullanus pseudeutropi $\mathrm{n}$. sp. differs from all the known forms of the genus in the possession of a transverse cuticular ridge and in the number and arrangement of anal papillae. Accordingly it is a regarded new with the specific name Cucullanus pseudeutropi $\mathrm{n} . \mathrm{sp}$. 
FAMILY - CAMALLANIDAE Railliet and Henry, 1915

\section{CAMALLANUS MASTACEMBELI n. sp.}

(Fig. 5-8)

Seven male and five female specimens were recorded from the intestine of a fresh water fish, Mastacembelus armatus (Lacep.) from river Gomti at Lucknow.

\section{Description :}

Worms smal!, elongated body, tapering towards both ends. Cuticle thin, finely striated. Mouth surrounded by six papillae, two lateral and four submedian in position. Buccal capsule sclerotized and formed by two buccal valves, each of which possesses 9 beaded longitudinal ridges of varying lengths in both sexes. Innermost ridges long with a gradual reduction in length towards outermost one. A strongly developed chitinous ring at junction of valves and œsophagus. A pair of tridents present. Esophagus consisting of a short anterior muscular portion and a long posterior glandular portion.

Male: Body 8.54 to $13.16 \mathrm{~mm}$. long, 0.19 to $0.20 \mathrm{~mm}$. wide. Dorsoventral diameter of head at its anterior angles 0.11 to $0.12 \mathrm{~mm}$. Valves of buccal capsule broader than long, 0.085 to $0.09 \mathrm{~mm}$. long, 0.10 to $0.11 \mathrm{~mm}$. wide. Chitinous ring 0.08 to $0.085 \mathrm{~mm}$. long, 0.010 to $0.020 \mathrm{~mm}$. wide. Tridents well developed, except for small middle prong, measuring 0.03 to $0.04 \mathrm{~mm}$ in length ; lateral prongs 0.07 to $0.09 \mathrm{~mm}$. long. Anterior club shaped muscular portion of œesophagus 0.48 to $0.59 \mathrm{~mm}$. long, 0.10 to $0.12 \mathrm{~mm}$. wide. Posterior glandular œsophagus 0.75 to $0.93 \mathrm{~mm}$. long, 0.10 to $0.11 \mathrm{~mm}$. wide. Entire œsophagus 0.85 to $1.49 \mathrm{~mm}$. long. Nerve ring surrounds anterior portion of œsophagus 0.22 to $0.29 \mathrm{~mm}$. from anterior extremity. Excretory pore posterior to nerve ring 0.48 to $0.59 \mathrm{~mm}$. from anterior extremity. Caudal alae broad beginning at cuticular swelling on ventral side of body extending upto tip of tail. Nine pairs of preanal, one pair of adanal and three pairs of postanal papillae. Preanal papillae situated almost at regular intervals and adanal papillae situated laterally at level of cloaca. Postnatal papillae close together in a group. Right spicule broad at anterior end, narrow and sharply pointed at its posterior end, measuring 0.42 to $0.76 \mathrm{~mm}$. in length. Left spicule absent.

Female: Body 16.25 to $24.88 \mathrm{~mm}$. long, 0.24 to $0.30 \mathrm{~mm}$. wide. Head 0.11 to $0.12 \mathrm{~mm}$. in diameter. Valves of buccal capsule 0.10 to $0.11 \mathrm{~mm}$. long, 0.12 to $0.13 \mathrm{~mm}$. wide. Chitinous ring 0.07 to $0.09 \mathrm{~mm}$. long, 0.02 to $0.03 \mathrm{~mm}$. wide. Lateral prongs of tridents 0.08 to $0.10 \mathrm{~mm}$. long. Middle prong 0.03 to $0.045 \mathrm{~mm}$. long. Anterior muscular œsophagus 0.52 to $0.61 \mathrm{~mm}$. long, 0.10 to $0.12 \mathrm{~mm}$. wide. Posterior glandula. ušst) hagus 0.78 to $0.93 \mathrm{~mm}$. long, 0.10 to $0.13 \mathrm{~mm}$. wide. Entire œsophagus 1.30 to $1.53 \mathrm{~mm}$. long. Nerve ring 0.20 to $0.26 \mathrm{~mm}$. and excretory pore 


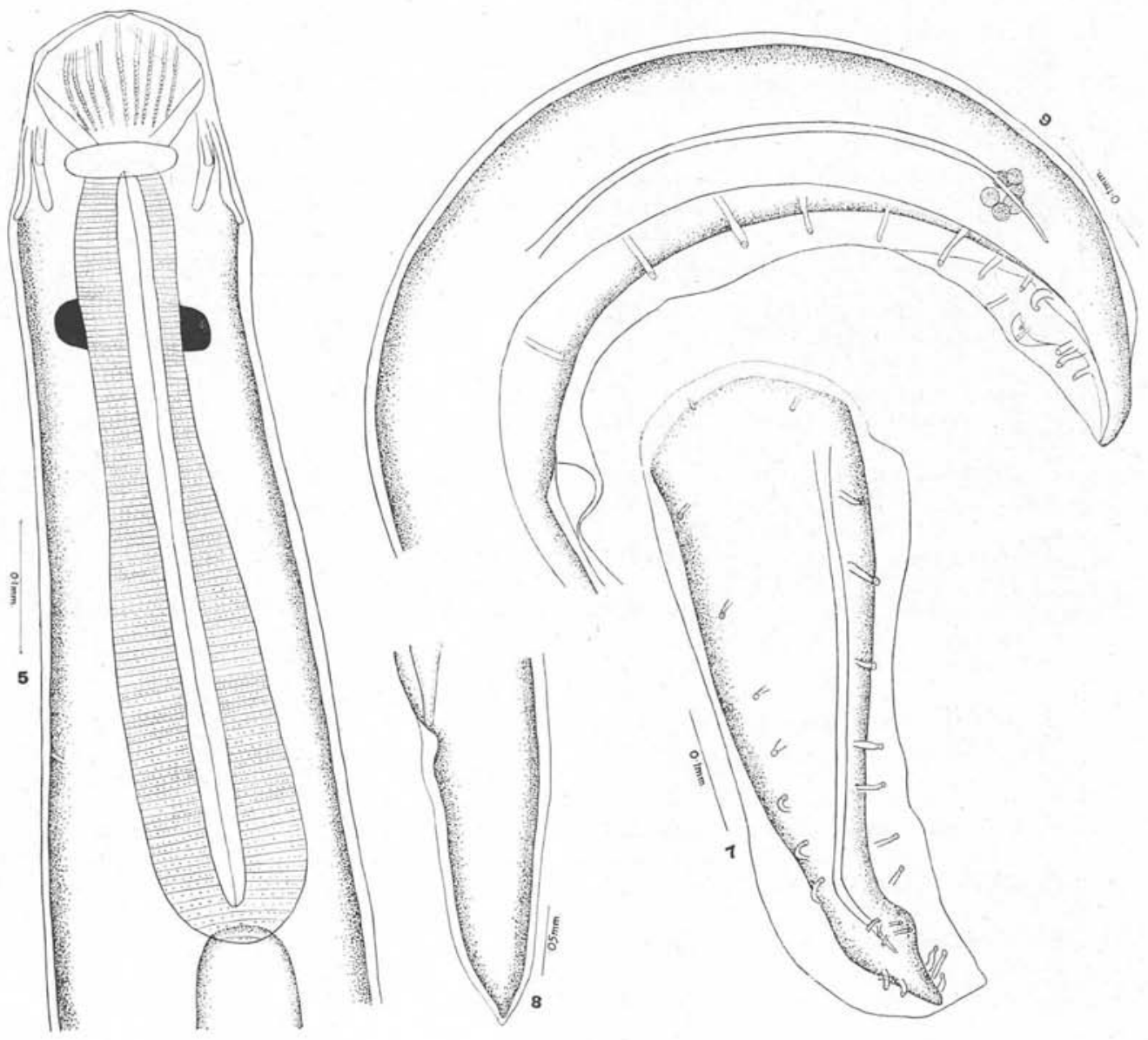

Fig. 5-8. - Camallanus mastacembeli n. sp.

Fic. 5. - Région antérieure du mâle. Vue latérale.

Fig. 6. - Extrémité caudale du mâle. Vue latérale

Fig. 7. - Extrémité caudale du mâle. Vue ventrale

Fig. 8. - Extrémité caudale de la femelle. Vue latérale.

Figs 5-8. - Camallanus mastacembeli n. sp.

FIG. 5. - Anterior region of male. Lateral view

Fig. 6. - Male tail. Lateral view

FIG. 7. - Male tail. Ventral view

FIG. 8. - Female tail. Lateral view 
TABLE I

Comparision of forms of the genus Camallanus Railliet and Henry, 1915

\begin{tabular}{|c|c|c|c|c|}
\hline \multirow{2}{*}{ Species } & \multirow{2}{*}{$\begin{array}{l}\text { Internal } \\
\text { longitudinal } \\
\text { ridges }\end{array}$} & \multirow{2}{*}{$\begin{array}{l}\text { Caudal } \\
\text { alae }\end{array}$} & \multicolumn{2}{|c|}{ Spicules } \\
\hline & & & Right & Left \\
\hline $\begin{array}{l}\text { C. anabantis Pearse, } 1933 \\
(=\text { Z. anabantis }) \text { Yeh, } 1960\end{array}$ & Beaded & Present & 0.11 & $0.58-0.65$ \\
\hline $\begin{array}{l}\text { C. sweeti Moorthy, } 1937 \\
(=\text { Z. sweetiof }) \text { Yeh, } 1960 .\end{array}$ & Beaded & Present & $0.21-0.30$ & $0.10-0.18$ \\
\hline C. unispiculus Khera, 1954 & Beaded & Absent & 0.63 & Absent \\
\hline $\begin{array}{l}\text { C. fernandoi }(=Z \text {. fernan- } \\
\text { doi) Yeh, } 1960 \ldots \ldots \ldots \ldots\end{array}$ & Beaded & $\begin{array}{c}\text { Male } \\
\text { unknown }\end{array}$ & $\cdots$ & $\ldots$ \\
\hline $\begin{array}{l}\text { C. } \text { kulasirii }(=Z . \text { kulasirii }) \\
\text { Yeh, } 1960 \ldots \ldots \ldots \ldots \ldots\end{array}$ & Beaded & Present & $0.15-0.19$ & $0.40-0.42$ \\
\hline $\begin{array}{l}\text { C. pearsei }(=Z . \quad \text { pearsei }) \\
\text { Yeh, } 1960 \ldots \ldots \ldots \ldots \ldots\end{array}$ & Beaded & $\begin{array}{c}\text { Male } \\
\text { unknown }\end{array}$ & $\cdots$ & $\cdots$ \\
\hline C. nodulosus Gupta, 1959 . & Beaded & Present & $0.44-0.45$ & $0.27-0.36$ \\
\hline C. thapari Gupta, 1959 .. & Beaded & Present & $0.44-0.46$ & $0.28-0.32$ \\
\hline C. mastacembeli n. sp. .. & Beaded & Present & $0.42-0.76$ & Absent \\
\hline C. ingilisi n. sp. ......... & Beaded & Present & $0.27-0.36$ & $0.37-0.46$ \\
\hline
\end{tabular}

at 0.50 to $0.51 \mathrm{~mm}$. from anterior extremity. Tail long tapering, 0.16 to $0.21 \mathrm{~mm}$. long. Vulva preequatorial, 6.7 to $9.03 \mathrm{~mm}$. from anterior extremity. Viviparous.

Host : Mastacembelus armatus (Lacep.).

Location: Intestine.

Locality: Lucknow.

\section{Discussion :}

Railliet and Henry (1915) established the genus Camallanus for C. lacustris (Zoega, 1776). Since the establishment of this genus a large number of species have been reported from various parts of World. Yamaguti (1961) has listed twenty 
species from fishes, eight species from amphibia and thirteen species from reptiles under the genus Camallanus. Ali (1956) erected a new genus Neocamallanus for Camallanides Baylis and Daubney, 1922 without tridents. Yeh (1960) considered the presence or absence of tridents as a variable character and therefore regarded Neocamallanus to be synonym of Camallanus. In the same year Yeh erected a new genus Zeylanema with the type species Z. anabantis (Pearse, 1933) to accomodate those species in which buccal capsule is armed with teeth like longitudinal ridges, caudal alae short and with two simple very unequal spicules.

Furtado and Fernando (1963) on the basis of the classification proposed by Yeh redescribed $Z$. anabantis from Ceylon. The author does not agree with the views of Yeh as the characters used by him for creating the genus are variable except the longitudinal ridges, armed with teeth in the buccal capsule. In C. sweeti Moorthy, 1937 (=Z. sweeti), C. nodulosus Gupta, 1959 and $C$. thapari Gupta, 1959 and $C$. inglisi n. sp., the spicules are subequal ; in Z. anabantis ( $=C$. anabantis) and Z. kulasirii Yeh, 1960, the spicules are very unequal while in $C$. unispiculus Khera, 1954 and $C$. mastacembeli n. sp. there is only one spicule. The male of Z. pearsei and Z. fernandoi Yeh, 1960 are unknown, so it is difficult to determine their generic position. In C. unispiculus and C. atridentus Khera, 1954 the caudal alae are absent while in others short or well developed. Hence the characters of a spicule equal or very unequal and short caudal alae are very unreliable for generic distinctions. (See table 1).

Therefore it is a matter of convenience to consider Zeylanema distinct from Camallanus rather than because of its taxonomic importance. I also disagree with Yeh who considers $C$. unispiculus to be a synonym of $C$. anabantis. $C$. unispiculus differs from $C$. anabantis in the size of body, in the number and arrangement of anal papillae, in the absence of caudal alae and in the presence of only one spicule. Yeh (1960) without comment transferred $C$. atridentus to Zeylanema. I disagree with this in that $C$. atridentus has longitudinal ridges smooth and extremely fine.

Eight species of Camallanus with internal longitudinal ridges armed with teeth in buccal capsule have been reported from fishes and amphibia. Of these two species are from amphibians namely $C$. thapari Gupta, 1959 and C. nodulosus Gupta, 1959 and the rest from fresh water fishes namely $C$. anabantis Pearse, $1933(=Z$. anabantis of Yeh, 1960), C. sweeti Moorthy, 1937 (=Z sweeti of Yeh, 1960), C. unispiculus Khera, 1954, C. fernandoi $(=Z$. fernandoi) Yeh, 1960, C. kulasirii $(=Z$. kulasirii) Yeh, 1960 and $C$. pearsei $(=Z$. pearsei) Yeh, 1960. C. mastacembeli n. sp. differs from the above mentioned species except $C$. unispiculus in the possession of a single spicule. It differs from $C$. unispiculus in having nine pairs preanal ; one adanal and three pairs postanal instead fourteen pairs preanal and two pairs postanal papillae, in the size of spicule, in having specimens of larger size upto $24.8 \mathrm{~mm}$. and in the possession of a well developed caudal alae. Further in new form the anterior œsophagus is smaller while in C. unispiculus anterior œsophagus is larger than posterior œsophagus. It is worthwhile to note that C. unispiculus Khera, 1954 and $C$. mastacembeli n. sp. are both recorded from Mastacembelus armatus. It is 
possible that both belong to the same species, however, on the basis of description and of the present status of Camallanid taxonomy, each of these is quite distinct.

(See table I).

\section{CAMALLANUS INGLISI n. sp.}

(Fig. 9-12)

Four male and seven female specimens were collected from the intestine of a frog, Rana tigrina from Lucknow.

\section{Description :}

Body elongated, slender, medium sized, tapering towards extremities. Cuticle thin, finely striated. Mouth surrounded by six papillae, two lateral and four submedian in position. Bivalve buccal capsule possess beaded chitinous ridges (9-11 in female, 10-12 in male). Ridges vary in length in both sexes. A strongly developed chitinous ring present at junction of valves and oesophagus. A pair of well developed tridents present. Esophagus consisting of a short anterior muscular and a long posterior glandular portion enlarged posteriorly.

Male : Body 6.25 to $8.11 \mathrm{~mm}$. long, 0.20 to $0.28 \mathrm{~mm}$. wide. Dorsoventral diameter of head at its anterior angles, 0.085 to $0.120 \mathrm{~mm}$. Valves of buccal capsule broader than long, 0.09 to $0.092 \mathrm{~mm}$. long, 0.01 to $0.015 \mathrm{~mm}$. wide. Tridents well developed except for smaller middle prong, measuring 0.025 to $0.028 \mathrm{~mm}$. in length; lateral prongs $0.06 \mathrm{~mm}$. long, 0.09 to $0.11 \mathrm{~mm}$. wide. Anterior club shaped muscular œesophagus 0.42 to $0.46 \mathrm{~mm}$. long. Posterior glandular œsophagus 0.33 to $0.46 \mathrm{~mm}$. long, 0.08 to $0.11 \mathrm{~mm}$. wide. Entire œsophagus 0.75 to $0.92 \mathrm{~mm}$. long. Nerve ring surrounds anterior portion of œsophagus 0.21 to $0.24 \mathrm{~mm}$. from anterior extremity. Excretory pore posterior to nerve ring 0.25 to $0.30 \mathrm{~mm}$. from anterior extremity. Caudal end curled ventrally to form a single turn of a spiral. Tail very short, 0.09 to $0.12 \mathrm{~mm}$. long with long bifid tip. Caudal alae broad beginning at cuticular swelling on ventral side of body, 0.41 to $0.67 \mathrm{~mm}$. from posterior end, extending upto tip of tail. Seven pairs of preanal, two pairs of paracloacal and five pairs of postanal papillae. Preanal and small paracloacal papillae situated almost at regular intervals. Postcloacal papillae small and sessile. Of postanal papillae two posterior pairs isolated, fourth pedunculated and fifth sessile. First three pairs of postcloacal papillae close together forming a group on each side. Spicules dissimilar and subequal. Right spicule relatively stout, 0.27 to $0.36 \mathrm{~mm}$. long with a barb or prong $0,05 \mathrm{~mm}$. long near its tip. Left spicule 0.37 to $0.46 \mathrm{~mm}$. long.

Female: Body 10.96 to $18.72 \mathrm{~mm}$. long, 0.32 to $0.48 \mathrm{~mm}$. wide. Dorsoventral diameter of head 0.14 to $0.18 \mathrm{~mm}$. Valves of buccal capsule 0.11 to $0.12 \mathrm{~mm}$. long, 0.16 to $0.19 \mathrm{~mm}$. wide. Chitinous ring 0.09 to $0.11 \mathrm{~mm}$. long, 0.01 to $0.02 \mathrm{~mm}$. wide. 


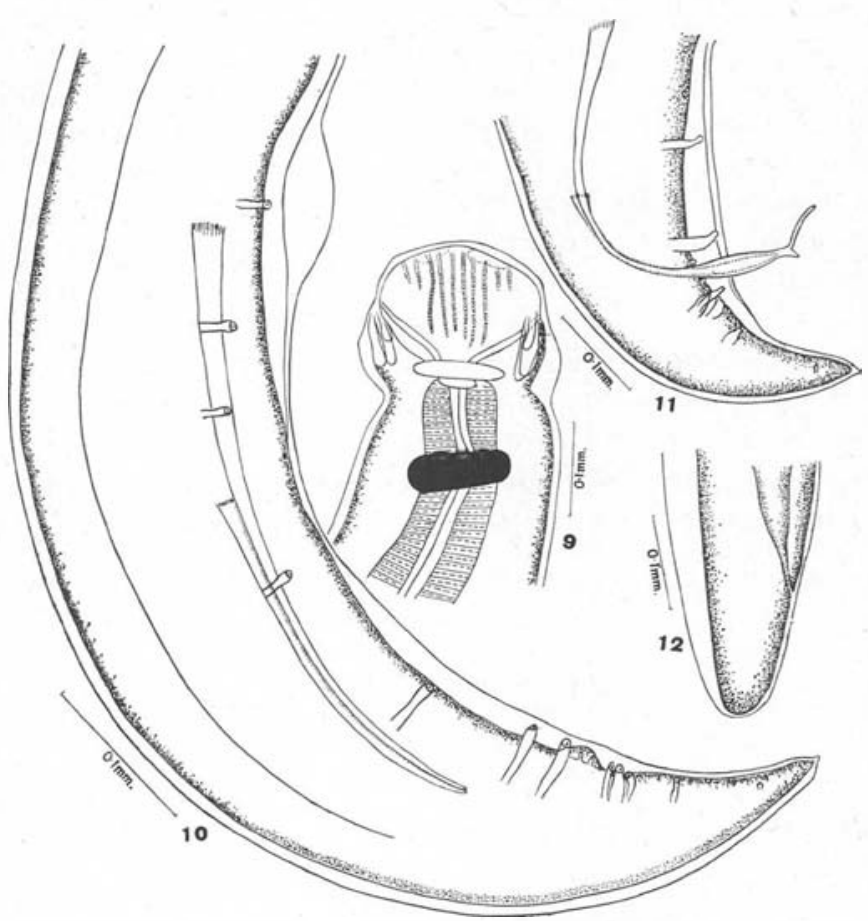

FIG. 9-12. - Camallanus inglisi n. sp.

Fig. 9. - Région antérieure du mâle. Vue latérale.

FIG. 10. - Extrémité caudale du mâle. Vue latérale.

FIG. 11. - Extrémité caudale du mâle. Vue latérale

Fig. 12. - Extrémité caudale de la femelle. Vue latérale

FIGS 9-12. Camallanus inglisi $\mathrm{n}$. sp.

FIG. 9. - Anterior region of male. Lateral view

Fig. 10. - Male tail. Lateral view

FIG. 11. - Male tail. Lateral view

FIG. 12. - Female tail. Lateral view

Lateral prongs of tridents 0.065 to $0.08 \mathrm{~mm}$. long; middle prong 0.03 to $0.038 \mathrm{~mm}$. long. Anterior muscular œsophagus 0.56 to $0.66 \mathrm{~mm}$. long, 0.09 to $0.15 \mathrm{~mm}$. wide. Posterior glandular œsophagus 0.45 to $0.59 \mathrm{~mm}$. long. Nerve ring 0.22 to 0.32 and excretory pore at 0.28 to $0.43 \mathrm{~mm}$. from anterior extremity. Tail long tapering 0.16 to $0.28 \mathrm{~mm}$. in length. Vulva preequatorial 4.96 to $9.52 \mathrm{~mm}$. from anterior extremity. Viviparous.

Host : Rana tigrina.

Location: Intestine.

Locality : Lucknow. 


\section{Discussion :}

Two species of the genus Camallanus with internal longitudinal ridges armed with teeth in the buccal capsule have been described so far from amphibian hosts viz. $C$. nodulosus Gupta, 1959 and $C$. thapari Gupta, 1959. The new form differs from both these forms in having specimens of both sexes of smaller size, in the possession of broad caudal alae and in the number and arrangement of pre and postcloacal papillae. The new form differs from $C$. nodulosus in having five pairs postanal papillae instead six pairs. In the new form there are five pairs of postcloacal papillae of which three anterior pedunculated postcloacal papillae are close together in a group while in $C$. nodulosus there are six pairs of postcloacal papillae of which four pedunculated postcloacal papillae are close together, in a group and the sixth is sessile. Further the new form differs from $C$. thapari in the possession of seven pairs of precloacal papillae instead six pairs and in having the most posterior post cloacal papillae sessile instead being pedunculated.

\section{CAMALLANUS BUFONIS n. sp.}

(Fig. 13-16)

Twelve male and seven female specimens were collected from the intestine of a toad Bufo sp. from Lucknow.

\section{Description :}

Body elongated, slender, medium sized tapering towards extremities. Cuticle thin, finely striated. Mouth surrounded by two lateral and four submedian papillae. Buccal capsule bivalved and possess 10 simple longitudinal ridges of varying lengths in both sexes. Head slightly tilted ventrad. A strongly chitinized ring at junction of valves and œsophagus. A pair of tridents conspicuous and sclerotized.

Male : Body 4.99 to $8.34 \mathrm{~mm}$. long, 0.16 to $0.26 \mathrm{~mm}$. wide. Dorsoventral diameter of head 0.09 to $0.14 \mathrm{~mm}$. Valves of buccal capsule broader than long 0.08 to $0.10 \mathrm{~mm}$. long, 0.10 to $0.14 \mathrm{~mm}$. wide. Tridents well developed except for small middle prong measuring 0.030 to $0.035 \mathrm{~mm}$. in length; lateral prongs 0.055 to $0.070 \mathrm{~mm}$. long. Anterior club shaped muscular portion of œsophagus 0.43 to $0.50 \mathrm{~mm}$. long, 0.08 to $0.11 \mathrm{~mm}$. wide. Posterior glandular œsophagus 0.30 to $0.45 \mathrm{~mm}$. long, 0.08 to $0.12 \mathrm{~mm}$. wide. Entire œsophagus 0.75 to $0.92 \mathrm{~mm}$. long. Nerve ring surrounds anterior portion of œsophagus 0.17 to $0.22 \mathrm{~mm}$. and excretory pore 0.19 to $0.29 \mathrm{~mm}$. from anterior extremity. Tail 0.090 to $0.155 \mathrm{~mm}$. long. Caudal alae broad beginning at cuticular swelling on ventral side of body extending upto tip of tail. Seven pairs of large pedunculated preanal papillae, two pairs of adanal and six pairs of postanal. A median papillae also found at level of cloaca. Preanal papillae situated almost at regular intervals and adanal papillae situated laterally at level of cloaca. Of postanal papillae, 

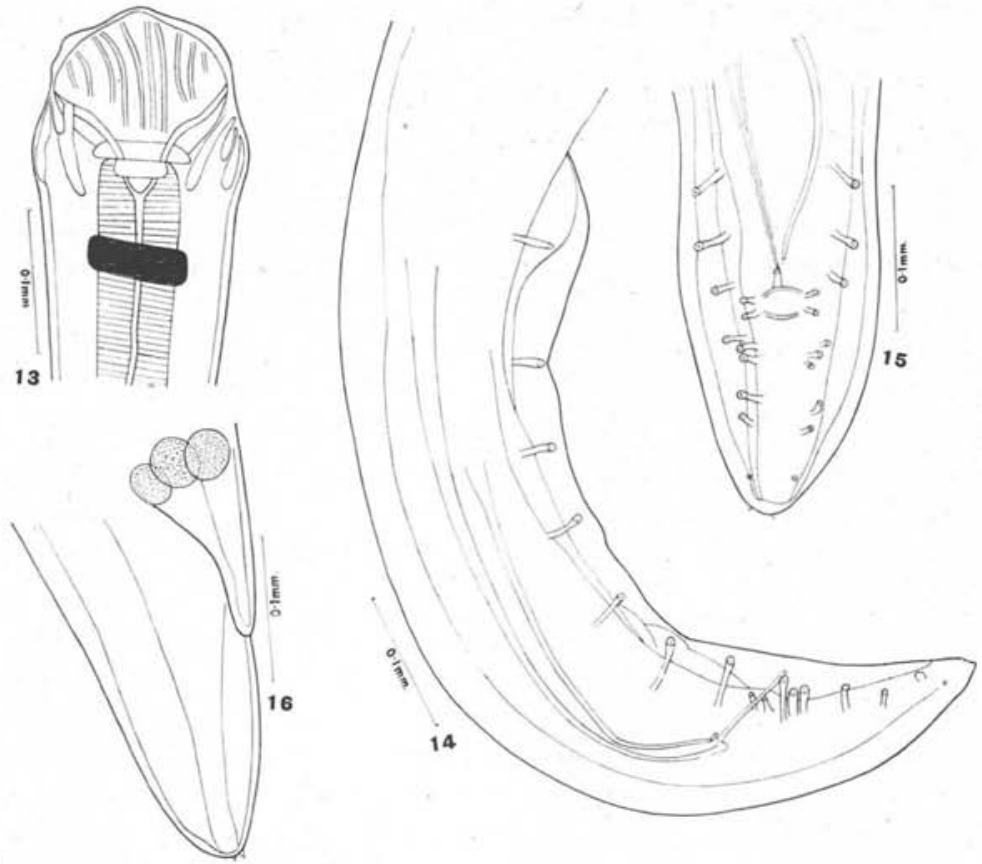

FIG. 13-16. - Camallanus bufonis n. sp.

Fig. 13. - Région antérieure du mâle. Vue latérale

Fic. 14. - Extrémité caudale du mâle. Vue latérale

FIg. 15. - Extrémité caudale du mâle. Vue ventrale

Fig. 16. - Extrémité caudale de la femelle. Vue latérale.

FIGS. 13-16. - Camallanus bufonis n. sp.

FIG. 13. - Anterior region of male. Lateral view

FIG. 14. - Male tail. Lateral view

FIG. 15. - Male tail. Ventral view

FIG. 16. - Female tail. Lateral view

three pairs close together in a group and three pairs situated one behind the other. A pair of phasmids observed at tip of tail. Spicules subequal and dissimilar. Right spicule broad, highly sclerotized, relatively large, 0.36 to $0.48 \mathrm{~mm}$. in length with a barb or prong, 0.054 to $0.06 \mathrm{~mm}$. long at its tip. Left spicule slender and thin, 0.28 to $0.40 \mathrm{~mm}$. in length.

Female : Body 8.128 to $12.624 \mathrm{~mm}$. long, 0.208 to $0.240 \mathrm{~mm}$. wide. Dorsoventral diameter of head 0.13 to $0.14 \mathrm{~mm}$. Buccal valves 0.10 to $0.13 \mathrm{~mm}$. long, 0.11 to $0.16 \mathrm{~mm}$. wide. Tridents well developed, middle prong 0.030 to $0.033 \mathrm{~mm}$. long ; lateral prongs 0.055 to $0.075 \mathrm{~mm}$. long. Anterior club shaped œsophagus 0.48 to $0.67 \mathrm{~mm}$. long, 0.06 to $0.10 \mathrm{~mm}$. wide. Posterior glandular œsophagus 0.30 to 
$0.62 \mathrm{~mm}$. long, 0.05 to $0.12 \mathrm{~mm}$. wide. Entire œsophagus 0.78 to $1.29 \mathrm{~mm}$. long. Nerve ring 0.23 to $0.26 \mathrm{~mm}$. and excretory pore at 0.26 to $0.30 \mathrm{~mm}$. from anterior extremity. Tail conical 0.128 to $0.176 \mathrm{~mm}$. long. Vulva nearly equatorial 3.848 to $6.042 \mathrm{~mm}$. from anterior extremity. Viviparous.

Host: Bufo sp.

Location : Intestine.

Locality : Lucknow.

\section{Discussion :}

Nine species of the genus Camallanus Raillet and Henry, 1915 without beaded longitudinal ridges in the buccal capsule have been reported from amphibians namely Camallanus nigrescens (von Linstow, 1906), Railliet and Henry, 1915, C. baylisi Karve, 1930, C. multiruga Walton, 1932, C. pipientis Walton, 1935, C. kaapstaadi Southwell and Krishner, 1937, C. mazabukae Kung, 1948, C. multilineatus Kung, 1948, C. ranae Khera, 1954 and $C$. johni Yeh, 1960. The new form differs from $C$. pipientis, $C$. mazabukae, C. kaapstaadi and $C$. johni in the possession of vulva preequatorial instead postequatorial. The new form can also be distinguished from $C$. multilineatus and C. multiruga in having anterior œsophagus larger than posterior œsophagus. The new form closely resembles to $C$. nigrescens, $C$. baylisi and $C$. ranae in the possession of anterior œsophagus larger than posterior œsophagus. However it differs from C. nigrescens in having two spicules instead one. The new form most closely resembles C. baylisi and $C$. ranae but can be distinguished in the number and arrangement of anal papillae. The new form differs from $C$. ranae in having six pairs of postcloacal papillae instead of five pairs and in the possession of a barb or prong 0.054 to $0.06 \mathrm{~mm}$. long at the tip of right spicule.

The new form has a close resemblance to $C$. baylisi in the number and arrangement of pre and post cloacal papillae but however differs from it in having a single median papillae at the level of cloaca, in having left spicule 0.28 to $0.40 \mathrm{~mm}$. long instead 0.18 to $0.23 \mathrm{~mm}$. long, in the absence of small spines at the tip of female tail and in having vulva slightly anterior to mid region of body.

Accordingly it is regarded as new with the specific name Camallanus bufonis n. sp.

\section{CAMALLANIDES PRASHADI (Baylis and Daubney, 1922)}

(Fig. 17-21)

Two male and a large number of female specimens were recovered from the intestine of a snake Ptyas mucosus (Linn.) at Lucknow. 


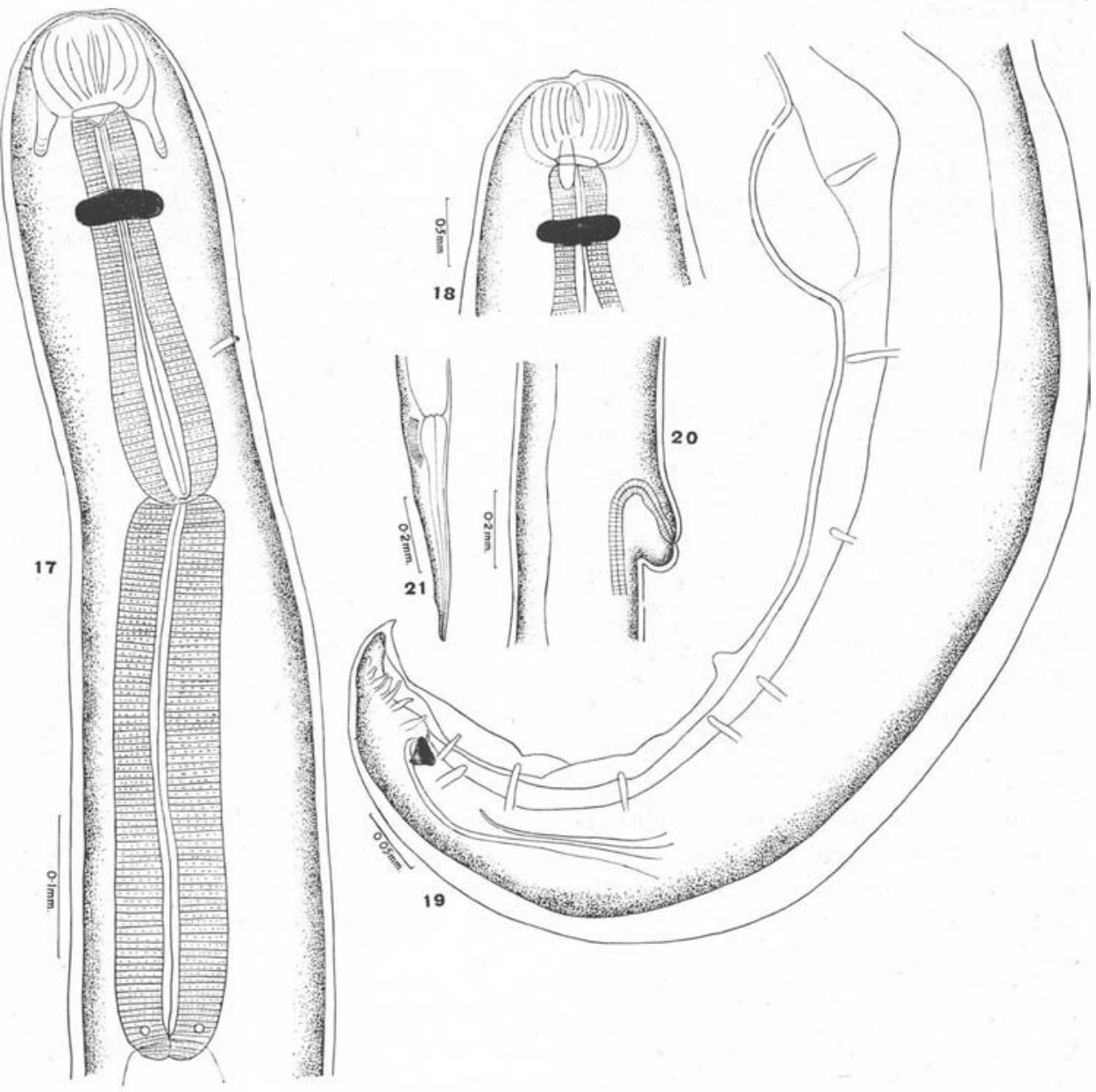

FIG. 17-21. - Camallanides prashadi Baylis et Daubney, 1922

Fig. 17. - Région antérieure du mâle. Vue latérale

Fig. 18. - Région antérieure du mâle. Vue latérale

FIg. 19. - Extrémité caudale du mâle. Vue latérale.

FIg. 20. - Région vulvaire. Vue latérale

Fig. 21. - Extrémité caudale de la femelle. Vue latérale

Figs. 17-21. - Camallanides prashadi Baylis and Daubney, 1922

FIG. 17. - Anterior region of male. Lateral view

FIG. 18. - Anterior region of male. Lateral view

FIG. 19. - Male tail. Lateral view

FIG. 20. - Vulvar region. Lateral view

FIG. 21. - Female tail. Lateral view 


\section{Description :}

Body elongated medium sized, slender and tapering towards extremities. Cuticle thin, finely striated. Mouth élongated dorsoventrally and surrounded by six papillae. Buccal capsule consists of two buccal valves each of which comprises four separated masses. Each valve consists of two chitinoid masses separated by a broad longitudinal groove. Buccal valves bear ten to twelve complete and incomplete longitudinal ridges in both sexes. A large stout chitinous ring present at junction of valves and œsophagus. Tridents simple pointed chitinous bodies of yellow colour lying opposite to edges of buccal valves. Dorsal and ventral chitinoid bodies, 0.10 to $0.15 \mathrm{~mm}$. in length.

Male : Body 6.74 to $7.29 \mathrm{~mm}$. long, 0.24 to $0.28 \mathrm{~mm}$. wide. Dorsoventral diameter of head 0.08 to $0.09 \mathrm{~mm}$. Buccal capsule 0.06 to $0.065 \mathrm{~mm}$. long, 0.080 to $0.085 \mathrm{~mm}$. wide. Posterior chitinous ring 0.040 to $0.042 \mathrm{~mm}$. in diameter. Length of rod 0.065 to $0.075 \mathrm{~mm}$. Anterior club shaped muscular œsophagus 0.29 to $0.30 \mathrm{~mm}$. long and 0.075 to $0.08 \mathrm{~mm}$. wide. Posterior cylindrical glandular œesophagus $0.42 \mathrm{~mm}$. long and 0.09 to $0.095 \mathrm{~mm}$. wide. Entire œsophagus 0.71 to $0.72 \mathrm{~mm}$. long. Nerve ring surrounds anterior portion of esophagus $0.14 \mathrm{~mm}$. and excretory pore at 0.19 to $0.22 \mathrm{~mm}$. from anterior end. Tail conical, pointed and curved ventrally to form a single turn of a spiral, 0.06 to $0.09 \mathrm{~mm}$. long. Caudal alae broad beginning at cuticular swelling on ventral side of body extending upto tip of tail. Fourteen pairs of caudal papillae with seven pairs preanal, two pairs paracloacal and five pairs postanal. Papillae pedunculated, rib like almost diminishing in size towards tip of tail. Preanal papillae situated almost at regular intervals. Paracloacal papillae curving inwards towards ventral side of cloaca. Postanal papillae arranged three in a group relatively large in size. Spicules dissimilar, subequal in size. Right spicule chitinized, 0.29 to $0.36 \mathrm{~mm}$. long, its tip curved into a hook. Left spicule chitinized, slender, tapering, 0.175 to $0.190 \mathrm{~mm}$. long. Gubernaculum yellow in colour, triangular, 0.028 to $0.029 \mathrm{~mm}$. long.

Female : Body 13.56 to $19.88 \mathrm{~mm}$. long, 0.40 to $0.48 \mathrm{~mm}$. wide. Dorsoventral diameter of head, 0.11 to $0.14 \mathrm{~mm}$. Buccal capsule 0.08 to $0.115 \mathrm{~mm}$. long, 0.11 to $0.14 \mathrm{~mm}$. wide. Posterior chitinous ring 0.055 to $0.070 \mathrm{~mm}$. in diameter. Anterior muscular œsophagus 0.31 to $0.40 \mathrm{~mm}$. long, 0.10 to $0.15 \mathrm{~mm}$. wide. Posterior glandular œsophagus 0.51 to $0.63 \mathrm{~mm}$. long, 0.10 to $0.15 \mathrm{~mm}$. wide. Entire œsophagus 0.88 to $0.99 \mathrm{~mm}$. long. Nerve ring 0.18 to $0.26 \mathrm{~mm}$. and excretory pore 0.32 to $0.56 \mathrm{~mm}$. from anterior extremity. Cervical papillae 0.52 to $0.86 \mathrm{~mm}$. from anterior extremity. Tail short 0.29 to $0.36 \mathrm{~mm}$. long, tapers gradually with exception of a very slight broadening out just before the pointed end. Vulva modified into tentacular appendage flattened dorsoventrally, projecting freely from body, 6.1 to $8.6 \mathrm{~mm}$. from anterior end. Viviparous.

Host: Ptyas mucosus (Linn.).

Location : Intestine.

Locality: Lucknow. 


\section{Discussion :}

Baylis and Daubney (1922) erected the genus Camallanides with the type species C. prashadi Baylis and Daubney, 1922. Khera (1954) divided the genus into two subgenera Camallanides and Procamallanides. Camallanides is characterised by the presence of dorsal and ventral chitinized bodies, while Procamallanides is based upon their absence.

My material is referred to $C$. prashadi in having dorsal and ventral chitinoid bodies but differs in being larger in size and in having spicules of larger size. These differences are considered variations within the species.

\section{TABLE II}

Measurements of Camallanides prashadi Baylis and Daubney, 1922 in mm.

\begin{tabular}{|c|c|c|c|c|}
\hline & \multicolumn{2}{|c|}{ Author's specimens } & \multicolumn{2}{|c|}{ Baylis and Daubney, 1922} \\
\hline & Male & Female & Male & Female \\
\hline Length $\ldots .$. & $6.94-7.29$ & $13.56-19.88$ & $5.8-6.6$ & $14.2-17.7$ \\
\hline Maximum & & & & \\
\hline width..... & $0.24-0.28$ & $0.4-0.48$ & $0.21-0.25$ & $0.40-0.47$ \\
\hline $\begin{array}{l}\text { Length of } \\
\text { spicules: }\end{array}$ & & & & \\
\hline Right $\ldots \ldots$ & $0.29-0.36$ & & 0.24 & \\
\hline Left $\ldots \ldots \ldots$ & $0.175-0.19$ & & 0.14 & \\
\hline
\end{tabular}

\section{Literature cited}

ALI (S. M.), 1956. - Studies on the nematode parasites of fishes and birds found in Hyderabad State. Ind. Jour. Helminth., 8: 1-83.

Baylis (H.) and Daubney (R.), 1922. - Report on the parasitic nematodes in the collection of the Zoological Survey of India. Mem. Ind. Mus., $7:$ 263-347.

Furtado (J. I.) and Fernando (C. H.), 1963. - A study of some Helminth parasites of fresh water fishes in Ceylon. Zeit. Fur. Parasitnk., 23 : 141-163.

KHERA (S.), 1954. - Nematode parasites of some Indian vertebrates. Ind. Jour. Helminth., 6: 27-113.

Railliet (A.) and Henry (A.), 1915. - Sur les Nématodes du genre Camallanus Railliet and Henry, 1915 (Cucullanus auct., non Mueller, 1777). Bull. Soc. Path. Exot., 8: 446452. 
YAmaguti (S.), 1961. - Systema Helminthum. Vol. 3. Nematodes of vertebrates, 1-1261, New York, Interscience.

YEH (L. S.), 1960. - On a collection of Camallanid nematodes from fresh water fishes in Ceylon. Jour. Helminth., 34 : 107-116.

YEH (L. S.), 1960. - On a reconstruction of the genus Camallanus Railliet and Henry, 1915. Jour. Helminth., 34 : 117-124.

[Département de Zoologie de l'Université de Lucknow (Indes)

Directeur : D ${ }^{r}$ S.-P. GuPTA] 